\title{
Babesiosis: under-reporting or case-clustering?
}

\author{
C.S. Clarke, E.T. Rogers ${ }^{1}$ and E.L. Egan \\ Departments of Haematology and 'Surgery, Galway Regional Hospital, Galway, Ireland.
}

\begin{abstract}
Summary: Babesiosis is a tick-borne protozoan disease which principally affects animals but occasionally affects humans. Cases have been reported from many parts of Europe with no evidence of case-clustering. We report the second case of babesiosis from a small area in the west of Ireland.
\end{abstract}

\section{Introduction}

There has been an increasing awareness in the medical and lay literature of tick-borne infectious diseases such as Lyme disease. We report the second case of a rarer tick-borne infection from a small area in the west of Ireland.

Babesiosis is a tick-borne protozoan disease which principally affects animals but which may occasionally affect humans. The condition has been described in both North America and Europe, but with different clinical and epidemiological features. ${ }^{1}$ Most American cases are due to Babesia microti, occur in a small circumscribed area in the north eastern United States, and follow a relatively benign course. Many, but not all, occur in people who have had a previous splenectomy. The vector is the deer tick, Ixodes dammini. The European cases are due principally to $B$. divergens, which is transmitted by the Ixodes ricinus tick. The disease has only been described in people who have had a previous splenectomy, and it follows a fulminant, generally fatal course. To date, cases have been reported from many parts of Europe with no evidence of case-clustering. Our case raises the question as to whether the incidence of babesiosis is in fact higher than is generally appreciated, or whether case-clustering also occurs in the European form of babesiosis.

\section{Case report}

A 58 year old married farmer was admitted to Galway Regional Hospital complaining of the passage of dark urine for one day. He was otherwise well. Splenectomy had been performed one year previously for a unilocular pseudocyst. He had received a blood trans-

Correspondence: C.S. Clarke, M.Med.Sci., M.R.C.P.I., Department of Haematology, Mater Misericordiae Hospital, Eccles' Street, Dublin 7, Ireland.

Accepted: 24 February 1989 fusion after his splenectomy, but no other blood products in the intervening year. Apart from a trip to England 6 years previously, he had never travelled abroad. There was no history of recent tick bites.

On admission his conjunctivae were mildly icteric. His skin was normally pigmented. Examination of his cardiovascular and respiratory systems revealed no abnormality. His abdomen bore the scars of previous surgery, but was otherwise normal. His urine had a smoky discolouration. Ward testing was positive for blood, bilirubin and urobilinogen. His full blood count was initially normal, with a haemoglobin level of $13.8 \mathrm{~g} / \mathrm{dl}$. His blood was grossly lysed. Serum urea and electrolytes were within normal limits. On the day of admission he developed fever, hypotension, oliguria and uraemia. The measured haemoglobin fell by $7.7 \mathrm{~g} / \mathrm{dl}$ over 24 hours to $6.1 \mathrm{~g} / \mathrm{dl}$, of which the plasma accounted for $4 \mathrm{~g} / \mathrm{dl}$. A Coombs' test was negative. Examination of a blood film showed that $80 \%$ of the red cells contained intracellular parasites which were morphologically identifiable as Babesia divergens. Exchange transfusions were commenced on the second hospital day, and intramuscular pentamidine on the third day. By the fourth hospital day, a blood film showed that less than $10 \%$ of the erythrocytes contained babesial parasites. Intravenous clindamycin and quinine sulphate were added. His renal function continued to deteriorate and he required peritoneal dialysis. His condition stabilized on the sixth day. However, on the seventh day he developed profound hypoglycaemia which, in the absence of other possible causes, was attributed to pentamidine. This was corrected with large amounts of intravenous glucose. However his level of consciousness deteriorated. $\mathrm{He}$ sustained a cardio-respiratory arrest and died on the twelfth hospital day.

At necropsy both kidneys were enlarged with microscopic evidence of acute tubular necrosis. Small thrombi were present throughout the viscera consistent with disseminated intravascular coagulation.

(C) The Fellowship of Postgraduate Medicine, 1989 


\section{Discussion}

To date six cases of babesiosis have been described in Europe. All but two of these were fatal. ${ }^{2-7}$ Though two of these were reported from Zagreb, Yugoslavia, they were due to different species - one occurring in an automobile mechanic in Zagreb due to $B$. bovis ${ }^{2}$ and the other due to $B$. divergens. ${ }^{4}$ Of the two cases reported from France, one was due to $B$. divergens, ${ }^{5}$ and the causative organism of the second is not specified. The first case of babesiosis in Ireland occurred in a man from Northern Ireland who contracted the disease while on a fishing holiday in Galway in the west of Ireland. ${ }^{3} \mathrm{He}$ was a deep sea fisherman. This was shown to be due to $B$. divergens. The present case represents the second case of babesiosis due to $B$. divergens contracted within 10 miles of Loughy Corrib in Galway. The occurrence in a small area of a rare infectious disease on two occasions suggests either that there is genuine caseclustering of the disease, due to special population characteristics of the infectious agent or the vector, or that the disease is actually more widespread than is generally appreciated, and that the low reported incidence is due to under-diagnosis. Redwater fever is common in cattle throughout Ireland; $1.7 \%$ of cattle in herds greater than 20 in number are affected per year, with a slightly higher incidence in the north and west of the country. ${ }^{8}$ The prevalence of the disease in cattle is as high as $30 \%$ in the north of Ireland, based on one sero-epidemiological study. ${ }^{9}$ It is unlikely that there is a significant regional variation in the prevalence of the asplenic state (though this hypothesis has not been tested). These facts all suggest that the low reported incidence is in fact due to under-reporting.

Our patient differs from many previously reported cases in that he was a long-term resident in an enzootic area. It is quite possible that the situation in humans resembles that in cattle where, in enzootic areas the animals most commonly affected are cattle introduced for breeding purposes, for slaughter, or in transit. ${ }^{10}$ It seems that in such areas very young animals are protected by maternally-acquired passive immunity. As this declines, gradual and repeated exposure to babesiae gives rise to active immunity. if previous exposure to babesiae does afford protection, as must occur in the vast majority of asplenic people living in such areas, one wonders why our patient was susceptible. It would be interesting to perform a seroepidemiological study similar to the one performed in cattle by Taylor et al. ${ }^{9}$ to determine whether or not contact with Babesia spp. is common in enzootic areas.

Our case raises the question as to the optimum treatment for this condition. As our patient showed clear evidence of improvement following exchange transfusions and pentamidine in terms of a reduction in parasite load, we would recommend these forms of treatment. We are unable to comment on the likely benefit of clindamycin and quinine sulphate.

Reports of successful treatments have generally occurred in cases of $B$. microti infection, which is generally a benign disease. The situation is also clouded by the anecdotal nature of most reports. Gombert et al. ${ }^{11}$ report six cases of infection due to $B$. microti. All six survived, five with no treatment. Sun $e t$ $a l .{ }^{12}$ report the successful use of exchange transfusion in $B$. microti infection. The use of pentamidine is supported by Franicioli et al..$^{13}$ who used it successfully in three non-splenectomized patients with $B$. microti infections. Wittener et al. ${ }^{14}$ suggest the use of a combination of quinine plus clindamycin based on the response of one patient with $B$. microti infection, but Smith et al. ${ }^{15}$ observed no benefit with it in a similar patient. $B$. divergens infection is generally fatal in humans, ${ }^{1}$ but cure has been achieved using a combination of chloroquine, exchange transfusions, haemodialysis and peritoneal dialysis. ${ }^{5}$

Although babesiosis is a rare disease in humans, we believe this is due to the rarity of the predisposing conditions - namely the post-splenectomy state, the absence of previous exposure which might afford protection and the seasonal pattern of the disease in cattle. ${ }^{10}$ Babesiosis represents a small but significant risk to the post-splenectomy patient. Such patients should probably be cautioned about the risk of visiting enzootic areas, particularly in the period from March to November when the disease is most prevalent in cattle. ${ }^{10}$ They should also be advised to adopt measures to limit exposure insofar as possible. Such measures might include some form of protective clothing. It may be that, as in the case of Lyme disease which is also transmitted by the Ixodes ricinus tick, prolonged feeding is necessary for transmission of the disease. If this were so, routine washing and a change of clothing after a period of exposure might reduce the risk of infection in asplenic individuals.

\section{Addendum}

Since submission of this manuscript we have diagnosed another case of babesiosis due to Babesia divergens in a farmer from the Galway region who had had a previous splenectomy.

\section{Acknowledgement}

We are grateful for the assistance of Dr S.H. Gillespie, London School of Tropical Medicine \& Hygiene, in managing this case. 


\section{References}

1. Rosner, F., Hossein-Zarabi, M., Benach, J. et al. Babesiosis in splenectomized adults. Am J Med 1984, 76: 696-701.

2. Skrabalo, Z. \& Deanovic, Z. Piroplasmosis in man: report of a case. Docum Med Geogr Trop 1957, 9: $11-156$

3. Fitzpatrick, J.E.P., Kennedy, C.C., McGeown, M.G. et al. Human case of piroplasmosis (babesiosis). Nature 1968, 217: 861-862.

4. Skrabalo, Z. Babesiosis (piroplasmosis). In: MarcialRojas, R.A. (ed.) Pathology of Protozoan and Helminthic Diseases. Williams \& Wilkins, Baltimore, 1971, pp. $232-233$.

5. Gorenflot, A., Piette, M. \& Marchand, A. Babesioses animales et santé humaine. Premier cas de babesiose humaine observe en France. Rev Med Vet 1976, 152: 289-297.

6. Bazin, C., Lamy, C., Piette, M. et al. Un nouveau cas de babesiose humaine. Nouv Presse Med 1976, 5: 799-800.

7. Entrican, J.H., Williams, H., Cook, I.A. et al. Babesiosis in man: a case from Scotland. $\mathrm{Br}$ Med J 1979, 2: 474.

8. Gray, J.S. \& Harte, L.N. An estimation of the prevalence and economic importance of clinical bovine babesiosis in the Republic of Ireland. Br Vet J 1985, 39: 75-78.
9. Taylor, S.M., Kenny, J. \& Strain, A. The distribution of Babesia divergens infection within the cattle population of Northern Ireland. Br Vet J 1982, 138: 384-392.

10. Donnelly, J. \& MacKellar, J.C. The effect of weather and season on the incidence of redwater fever in cattle in Britain. Agricultural Meteorology 1970, 7: 5-17.

11. Gombert, M.E., Goldstein, E.J., Benach, J.L. et al. Human babesiosis - clinical and therapeutic implications. JAMA 1982, 248: 3005-3007.

12. Sun, T. Tenenbaum, M.J., Greenspan, J. et al. Morphological and clinical observations in human infection with Babesia microti. J Infect Dis 1983, 148: 239-248.

13. Franicioli, P.E., Keithly, J.S., Jones, T.C. et al. Response of human babesiosis to pentamidine therapy. Ann Int Med 1981, 94: 326-330.

14. Wittener, M., Rowin, K.S., Tanowitz, H.B. et al. Successful chemotherapy of transfusion babesiosis. Ann Int Med 1982, 96: 601-604.

15. Smith, R.P., Evans, A.T., Papovsky, et al. Transfusionacquired babesiosis and failure of antibiotic treatment. JAMA 1986, 256: 2726-2727. 